\title{
MORATORIA ON THE USE OF GENETIC TESTS AND FAMILY HISTORY FOR MORTGAGE-RELATED LIFE INSURANCE
}

\author{
By A. S. Macdonald
}

\begin{abstract}
The Human Genetics Commission intends to study the use of family history in underwriting, regarding it as genetic information in a broad sense. We survey the developments in genetics and insurance that led up to this decision. We propose a model for studying the possible costs of adverse selection in the mortgage-related life insurance market (which is important in the United Kingdom) with and without moratoria on the use of family history. We consider both level and decreasing term assurances, finding that the cost of adverse selection is slightly higher for the latter. Several assumptions about mutation penetrance, incidence of additional mortality, prevalence of genetic testing and insurance-buying behaviour are considered. Overall we conclude that: (a) a moratorium on genetic test results alone will lead to negligible adverse selection costs; while (b) a moratorium extended to family history will lead to premium increases just by redefining underwriting classes, with adverse selection being possible as well, but only in extreme circumstances would all premium increases be likely to exceed about $10 \%$. However, we give examples in a model of a smaller life insurance market that show that our benign conclusions might not apply more generally.
\end{abstract}

\section{KEYWORDS}

Adverse Selection; Family History; Genetic Tests; Moratoria; Mortgage Protection Insurance

\section{CONTACT ADDRESS}

A. S. Macdonald, Department of Actuarial Mathematics and Statistics, Heriot-Watt University, Edinburgh EH14 4AS, U.K. Tel: +44(0)131-451-3209; Fax: +44(0)131-451-3249; E-mail: A.S.Macdonald@ma.hw.ac.uk

\section{INTRODUCTION}

1.1 The Human Genetics Commission and Family History

In May 2001, the Human Genetics Commission (HGC) made interim recommendations to the Government (HGC, 2001) relating to genetics and insurance. These included a moratorium on using DNA-based genetic test results in underwriting, but not family history. However, it said: "During the moratorium period HGC will address the issue as to how family history information is used by insurers." If the earlier part of the debate on genetics and insurance was driven by DNA-based tests, it is surely now turning to broader definitions of genetic information (see Zimmern (2001) for a discussion). 
Some previous studies of life insurance and genetics (Macdonald, 1997, 1999) also focused on DNA-based testing, and did not model family history. At least one study (Subramanian et al., 2000), of breast and ovarian cancer, did model family history, concluding that it was more important than access to DNA-based tests for mutations in the BRCA1 and BRCA2 genes. The aim of this paper is to extend these studies in two ways:

(a) by modelling the underwriting of late-onset Mendelian disorders based on family history, and the cost of extending the moratorium to family history; and

(b) to compare the costs of adverse selection based on level or decreasing term assurances.

Our second aim derives from the importance of life insurance in connection with house purchase in the United Kingdom. It is in this context that life insurance is sometimes claimed to be a necessity of everyday life, which is one of the strongest arguments in favour of allowing free access to it. All previous studies have considered level term assurances only, but if a mortgage loan is repaid over its term (as is now once more common) a decreasing term assurance will give adequate cover.

\subsection{Genetic Information}

Genetic information could mean:

(a) the result of a (reliable) DNA-based test;

(b) the detection of the product of a mutated gene, such as kidney cysts in adult polycystic kidney disease (APKD), detectable by ultrasound;

(c) a family history of a Mendelian disorder, such as Huntington's disease, (HD) that implies a probability of carrying a mutation; or

(d) a family history of a complex non-Mendelian disorder, such as heart disease, whose genetic component will be hard to isolate from shared environmental factors.

The Code of Conduct introduced by the Association of British Insurers (ABI) in 1997 used the narrowest definition of a genetic test, namely: "an examination of the chromosome, DNA or RNA to find out if there is an otherwise undetectable disease related genotype, which may indicate an increased chance of that individual developing a specific disease in the future" (ABI, 1999).

\subsection{Recent Developments in the United Kingdom}

The main features of the ABI's Code of Conduct were:

(a) a ban on asking anyone to take a genetic test;

(b) a ban on offering below-ordinary rates on the basis of genetic test results;

(c) a list of eight (later seven) disorders that the ABI's genetics adviser regarded as significant for insurers; and 
(d) a moratorium on the use of the specified tests for life insurance of up to $£ 100,000$ in connection with a mortgage.

In 1997 the Human Genetics Advisory Commission (HGAC) asked the Government to place a moratorium on the use of genetic test results (HGAC, 1997). The Government disagreed, but set up a Genetics and Insurance Committee (GAIC) charged with assessing applications from insurers (in practice, the ABI) to be allowed to use specific test results for specific types of insurance. GAIC demanded medical and actuarial evidence of the reliability and relevance of any test; it decided that this meant evidence that an adverse result implied extra mortality of at least $50 \%$ or extra morbidity of at least $25 \%$. In late 2000 GAIC approved the first application, in respect of $\mathrm{HD}$ and life insurance.

Also in 2000, the HGAC and other advisory bodies were combined into the HGC, which made insurance its first priority and consulted widely. It meant to leave GAIC alone, and to consider the wider social and ethical issues, but, in the event, much of the debate was critical of GAIC. Specifically:

(a) GAIC looked only at the increased individual risk implied by adverse test results, and did not consider countervailing factors, such as the overall cost to the industry of ignoring test results.

(b) Because only the ABI was likely to submit applications, GAIC was effectively bound to its narrow definition of genetic information.

(c) The thresholds that GAIC used, although based on industry practice, were thought by some to be low.

(d) GAIC did not ask how an adverse test result should be interpreted, or what reasonable underwriting practice might be, it just said 'yes' or 'no'.

(e) Family history was not considered at all; 'relevance' was not relative to the information already available, but only relative to population average risk.

(f) The application that GAIC had approved had been strongly criticised in some respects by the actuarial peer-reviewer, and it was not clear that actuarial evidence had to meet the standards of rigour expected of medical evidence.

Perhaps more important than any of these, however, was the ABI's interpretation of what had been agreed with the Government when GAIC was set up. Rather than telling its members not to ask about test results until GAIC had accepted an application, it told them that they could continue to do so until GAIC had rejected an application; in that event, any excessive premiums that had been paid should be refunded. Few others agreed with this interpretation. Nor was the logic clear: because the disorders in question were rare, and family history could be used, and only people with a clear family history would ever be tested, the likely cost of a temporary abstention was negligible. To many, it appeared that insurers were simply using tests 
that they had agreed not to use. The ABI's stance and GAIC's apparent leniency towards criteria and actuarial evidence convinced some who supported an evidence-based approach that they should oppose the industry more vigorously.

Eventually, the ABI agreed to limit its list to tests in respect of which applications had reached GAIC by the end of 2000, which, in the event, were for HD, breast/ovarian cancer (the BRCA1 and BRCA2 genes) and earlyonset Alzheimer's disease (EOAD) (the APP and PSEN-1 genes). The existing practice continued in respect of these.

In April 2001, the Select Committee on Science and Technology (SCST) of the House of Commons issued a report strongly critical of the industry (SCST, 2001). It disagreed with the ABI's interpretation of the GAIC process, and took the withdrawal of four disorders to imply uncertainty about the relevance for insurance of genetic tests in general. It drew the same conclusion from the differences of opinion observed among the ABI's members; some insurers did not ask for genetic test results anyway. When the HGC reported, in May 2001, it recommended a three-year moratorium on the use of genetic test results, but not (yet) family history, and for the ceiling to be increased above $£ 100,000$ for all kinds of insurance, whether or not in connection with a mortgage. It also announced its intention to review the use of family medical history in 2004. In the event, and following more positive discussions with the Government, the ABI agreed to a five-year moratorium with a ceiling of $£ 500,000$ for life insurance and $£ 300,000$ for other forms of insurance.

\subsection{Mortgage-Related Life Insurance}

Although life insurance is not absolutely necessary in order to obtain a mortgage, it is desirable both from the borrower's and the lender's points of view. Its importance can be gauged from the terms of the ABI's original moratorium (Section 1.3). Macdonald (1997, 1999) concluded that multifactorial disorders were unlikely to be significant for life insurance, and identified over-insurance (larger than average sums assured) as the most likely reason for losses from adverse selection. This gave some support for upper limits on the sums assured that could be obtained without disclosure of genetic information. However, this and other studies based on level term assurance might overstate the importance of genetic information for mortgage-related insurance, for several reasons:

(a) over-insurance is less likely, because the sum assured is linked to the price of a house;

(b) if the mortgage is to be repaid by an endowment assurance, the extra premium in respect of the life insurance element will usually be a very small proportion of the total premium; and

(c) if a decreasing term assurance (matching the outstanding loan) is used, as is common, the sum assured will be falling while the additional risk increases. 
In particular, the GAIC criterion of $50 \%$ extra mortality ignores the actual incidence of mortality losses. It seems worthwhile to consider mortgage protection insurance separately.

\subsection{Contents}

In Section 2 we set out a simple model of a term assurance market, incorporating genetic testing and insurance purchase between ages 20 and 50 . In Section 3 we study the costs of adverse selection, comparing level and decreasing term assurances. In view of the conclusions of Macdonald (1997, 1999), we restrict ourselves to late-onset genetic disorders; clearly multifactorial disorders will have no greater impact than that discussed there. Our conclusions are in Section 4.

\section{A Model of a Term Assurance Market}

\subsection{How a Moratorium Might Affect Insurance Markets}

We suppose the whole population is divided into three sub-populations, labelled $i=1,2,3$, representing different risk groups as follows:

(a) those who have no family history and are presumed not to be at risk $(i=1)$;

(b) persons at risk because of family history who are not mutation carriers $(i=2)$; and

(c) persons at risk because of family history who are mutation carriers $(i=3)$.

Before a moratorium, the population is divided into a number of underwriting classes, according to the risk factors then in use. Within each underwriting class, we assume that everyone is charged the same premium, meeting the equivalence principle: the expected present value (EPV) of premiums equals the EPV of benefits. We do not necessarily assume that each class is homogeneous. Our 'pre-moratorium' model has two underwriting classes, namely those not at risk and those who have a family history; the latter is not homogeneous, because not everyone at risk will carry a gene mutation. This is No. 2 in Table 1, before the discovery of genetic tests.

A moratorium might affect insurance markets in two ways; each might lead to premium increases, that we have to consider separately. First, it will change the composition of the underwriting classes. In Table 1, No. 4 represents the current position, with a moratorium on genetic test results only, while No. 5 represents the (perhaps more realistic) possibility that persons with negative test results will be allowed ordinary rates. No. 3 represents extending the moratorium to family history. If the 'not at risk' sub-population $(i=1)$ defines the ordinary rates (OR) class before a moratorium (those not charged any extra premium), then the first effect of 
Table 1. Possible underwriting classes with three sub-populations: $i=1$ not at risk; $i=2$ at risk, but not mutation carriers; $i=3$ at risk and mutation carriers: (T) denotes persons who have had a genetic test and

(U) denotes persons who have not

\begin{tabular}{|c|c|c|c|c|c|c|c|}
\hline \multirow[b]{2}{*}{ No. } & \multirow[b]{2}{*}{$\begin{array}{l}\text { Genetic } \\
\text { testing } \\
\text { exists? }\end{array}$} & \multicolumn{3}{|c|}{ Factors allowed in underwriting } & \multicolumn{3}{|c|}{ Composition of underwriting classes } \\
\hline & & $\begin{array}{l}\text { Family } \\
\text { history }\end{array}$ & $\begin{array}{c}\text { Negative } \\
\text { test } \\
\text { results }\end{array}$ & $\begin{array}{l}\text { Positive } \\
\text { test } \\
\text { results }\end{array}$ & OR class & $\begin{array}{c}\text { Rated for } \\
\text { family history }\end{array}$ & $\begin{array}{l}\text { Rated for } \\
\text { genetic test }\end{array}$ \\
\hline 1 & No & No & $\mathrm{n} / \mathrm{a}$ & $\mathrm{n} / \mathrm{a}$ & $i=1,2,3$ & & \\
\hline 2 & No & Yes & $\mathrm{n} / \mathrm{a}$ & $\mathrm{n} / \mathrm{a}$ & $i=1$ & $i=2,3$ & \\
\hline 3 & Yes & No & No & No & $i=1,2,3$ & & \\
\hline 4 & Yes & Yes & No & No & $i=1$ & $i=2,3$ & \\
\hline 5 & Yes & Yes & Yes & No & $\begin{array}{l}i=1 \text { and } \\
i=2(\mathrm{~T})\end{array}$ & $\begin{array}{l}i=3 \text { and } \\
i=2(\mathrm{U})\end{array}$ & \\
\hline 6 & Yes & Yes & Yes & Yes & $\begin{array}{l}i=1 \text { and } \\
i=2(\mathrm{~T})\end{array}$ & $\begin{array}{l}i=2(\mathrm{U}) \text { and } \\
i=3(\mathrm{U})\end{array}$ & $i=3(\mathrm{~T})$ \\
\hline
\end{tabular}

a moratorium might be to extend the OR class, and standard premium rates might increase. This might be compounded if, in the past, those at risk had bought less insurance than average, because they had been charged higher premiums. We should not call it adverse selection if they now revert to average levels of insurance, although this would be a change in behaviour.

In addition, those at risk might go further than reverting to average insurance-buying behaviour, and be even more likely to buy insurance, leading to adverse selection. Thus, we have three markets to consider:

(a) a market with no moratorium;

(b) a market with a moratorium, but no adverse selection; and

(c) a market with a moratorium and adverse selection.

\subsection{The Model}

Figure 1 shows a discrete-state, continuous-time model of a term assurance market, incorporating genetic testing. There is one such model for each sub-population, $i=1,2$ and 3 .

The proportion of lives who start (are born) in State $i 0$ is $p_{i}$, and we suppose that $p_{2}=p_{3}$. In other words, we assume that each sibling in a generation known to be at risk has the Mendelian probability $1 / 2$ of inheriting a mutation from a parent known to be affected. The truth could be more complicated; for example:

(a) the last affected relative could be in the grandparents' generation; or

(b) gene mutations could account for a proportion only of cases of the disease (for example, BRCA1 and BRCA2 mutations account for about $5 \%$ of breast cancers) and a family history could be the chance result of sporadic cases. 


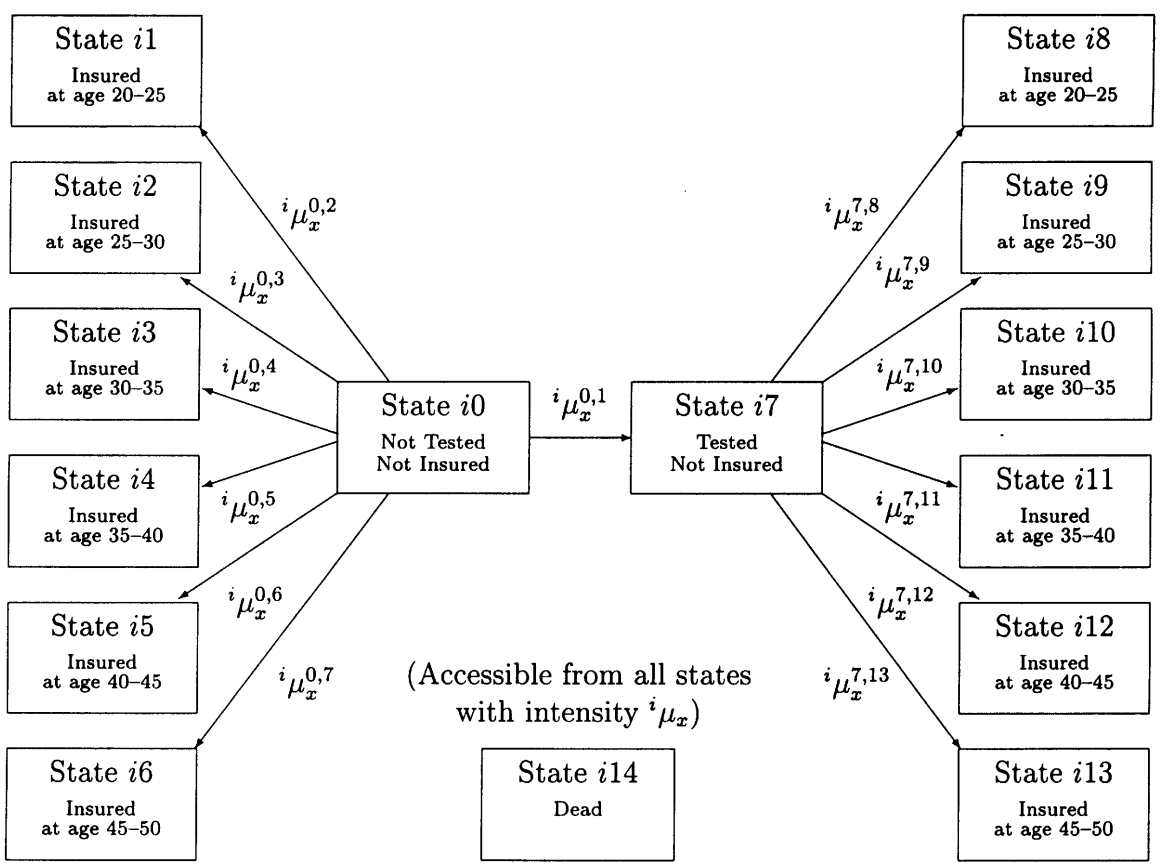

Figure 1. A Markov model for genetic testing and insurance purchase between ages 20 and 50, in the $i$ th of three sub-populations representing risk groups; the dead state $i 14$ is accessible from all other states with intensity ${ }^{i} \mu_{x}$; the arrows are omitted for clarity

We suppose that at age 20 an individual has not bought life insurance and has not had a genetic test. Subsequently, at any time before age 50, they may buy life insurance without taking a genetic test, entering one of states $i 1$ to $i 6$, depending on their age (for reasons to be explained later); or they may have a genetic test, entering state $i 7$, and may then buy insurance, entering one of states $i 8$ to i13. At any time they might die, entering state $i 14$, and if, insured, the sum assured will be paid. We suppose that all insurance contracts expire at age 60 .

Here 'genetic test' means anything that confirms the presence of a mutation, including non-DNA-based tests such as ultrasonic detection of APKD that are not covered by the ABI's Code of Conduct. Family history is excluded, except the remote chance of onset in an identical twin.

Some other studies (Pritchard, 1997; Subramanian et al., 2000) have assumed that more actions are available to the policyholder, such as 
increasing or reducing the amount of existing cover after being tested. We do not do so here, because the link to house purchase makes such actions less likely (they could easily be added to the model, however).

We suppose that the force of interest is $\delta=0.05$, representing both the insurance company's return on its assets and the mortgage rate of interest. Therefore, if repayment of a mortgage of amount $£ 1$ starts at age $y$, the outstanding loan at age $y+t$ is:

$$
\frac{1-e^{-\delta(60-y-t)}}{1-e^{-\delta(60-y)}}
$$

(see Figure 2). This is the sum assured under a decreasing term assurance; the sum assured under a level term assurance is always $£ 1$.

It is simplest if the model is Markov, and transition intensities and all cash flows depend on attained age alone. Therefore:

(a) The premiums are not level (level premiums would depend on the age at entry), but in state $i j$ are payable at a $\operatorname{rate}^{i} b_{x}^{j}$ depending on age alone. ${ }^{i} b_{x}^{j}$ will be determined as an average mortality rate over the states covered by a given underwriting class. This is like the current-cost charging often used for unit-linked contracts in the U.K.

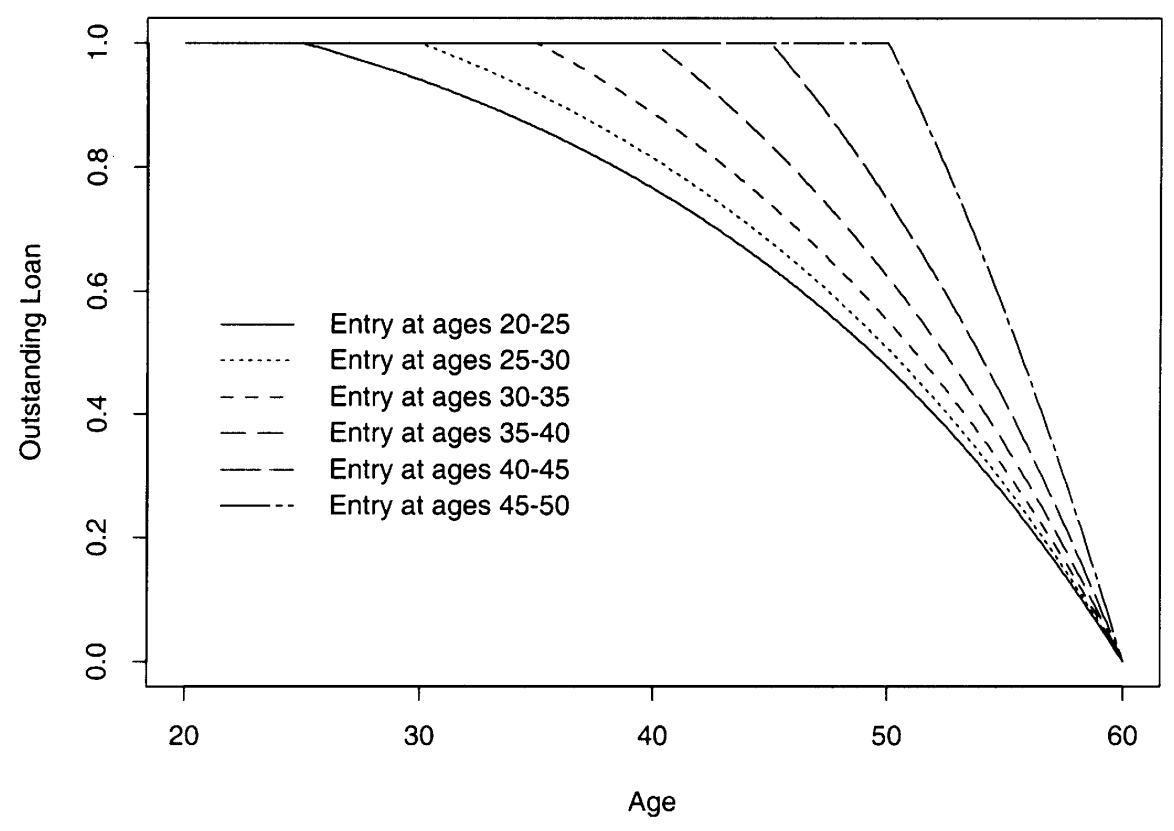

Figure 2. Decreasing sums assured, depending on age at entry 
(b) The sum assured in equation (1) depends on the age at which repayment of the loan starts. Therefore we assume that, while loans can be taken out at any age, repayment starts at the next quinquennial age. For example, someone who takes out a loan at age 33 will start repaying it at age 35 . This lets us divide the insured states into five-year age groups, for each of which the sum assured depends on attained age only. A similar device was used by Macdonald, Waters \& Wekwete (2003) to model family histories in which relatives' ages at onset were relevant.

\subsection{Overall Aim in Choosing Assumptions}

Most of our assumptions must be hypothetical, so we do not aim to produce an accurate model of any real insurance market or any particular genetic disorder. Rather, as in Macdonald (1997), we choose assumptions that we believe to be extreme, and far worse than may be expected in practice. In this way, our modelled costs of adverse selection may be regarded as plausible upper limits.

\subsection{Mortality}

We assume a 'baseline' force of mortality, applicable to the OR group and to those at risk who are not mutation carriers, of $60 \%$ of the following Gompertz approximation to the AM80 ultimate mortality table (see Macdonald \& Pritchard, 2000):

$$
{ }^{1} \mu_{x}=0.000094116 e^{0.084554 x} .
$$

For the mutation carriers we shall make a range of mortality assumptions of the form ${ }^{3} \mu_{x}={ }^{1} \mu_{x}+{ }^{g} \mu_{x}$, where ${ }^{g} \mu_{x}$ is the additional mortality associated with the disorder. We assume that ${ }^{g} \mu_{x}=0$ below age 30 , and that the penetrance of the mutation by age 60 is $75 \%, 50 \%$ or $25 \%$. Here penetrance means the probability of death rather than of onset of the disease; $75 \%$ is therefore high for some conditions.

To determine the functional form of ${ }^{g} \mu_{x}$, we assume that its associated survival function $\exp \left(-\int_{30}^{t} g \mu_{x} d x\right)$ is linear. This is likely to overstate mortality at younger ages, so errs in the right direction. Let $P=1-\exp \left(-\int_{30}^{60} \mu_{x} d x\right)$ be the penetrance at age 60 ; then:

$$
{ }^{g} \mu_{30+t}=\frac{P}{30(1-P t / 30)} .
$$

\subsection{Market Size}

The rate at which insurance is normally purchased determines whether adverse selection takes place in a small market or in a large market. Macdonald (1997) used an annual rate of 0.05, while Macdonald, Waters \& 
Wekwete (2001) used annual rates of $0.001,0.01$ and 0.05 to represent small, medium and large markets for critical illness (CI) insurance. Life insurance is a large, mature market, so we will use rates of 0.05 to represent the status quo, and 0.01 to illustrate a smaller market. In practice, insurance tends to be purchased at younger ages rather than at older ages (Yang, 2000), but a level rate such as we have used will overstate losses from adverse selection.

\subsection{Procedure}

Suppose that a life in the $i$ th sub-population is in state $i j$ at age $x$. A premium is paid continuously at annual rate ${ }^{i} b_{x}^{j}$, and on transition to state $i k$ a benefit of ${ }^{i} b_{x}^{j k}$ will be paid. Let ${ }_{t}^{i} p_{x}^{j k}$ be the probability that a person in state $i j$ at age $x$ is in state $i k$ at age $x+t$ (the 'occupancy probabilities'), and let ${ }^{i} V_{x}^{j}$ be the statewise prospective policy values. These quantities satisfy respectively Kolmogorov's forward equations:

$$
\frac{d}{d t}{ }_{t}^{i} p_{x}^{j k}=\sum_{l \neq k}{ }_{t}^{i} p_{x}^{j l} \quad{ }^{i} \mu_{x+t}^{l k}-\sum_{l \neq k}{ }_{t}^{i} p_{x}^{j k} \quad{ }^{i} \mu_{x+t}^{k l}
$$

with boundary conditions ${ }_{0}^{i} p_{0}^{j k}=p_{i}$ if $j=k=0$, zero otherwise; and Thiele's equations:

$$
\frac{d}{d x}{ }^{i} V_{x}^{j}=\delta^{i} V_{x}^{j}+{ }^{i} b_{x}^{j}-\sum_{k \neq j}{ }^{i} \mu_{x}^{j k}\left({ }^{i} b_{x}^{j k}+{ }^{i} V_{x}^{k}-{ }^{i} V_{x}^{j}\right)
$$

with boundary conditions ${ }^{i} V_{x}^{j}=0$ at expiry (for term assurances). The procedure is:

(a) Solve the Kolmogorov equations forwards. An underwriting class is defined by a set $\mathcal{C}$ of states in which a person will, or would upon application, be charged the same premium rate (see Table 1). At age $x$, that rate of premium per unit sum assured will be in proportion to the weighted average mortality rate:

$$
\text { Premium rate at age } x=\sum_{i j \in \mathcal{C}} p_{i}{ }_{x}^{i} p_{0}^{0 j}{ }^{i} \mu_{x} / \sum_{i j \in \mathcal{C}} p_{i}{ }_{x}^{i} p_{0}^{0 j} .
$$

(b) Solve Thiele's equations backwards from age 60 to any age $x$, using the rates of premium found above. The average policy value, weighted by the occupancy probabilities in non-dead states at age $x$, is the EPV of the loss in an insurance market operating between age $x$ and age 60 ; by setting premiums to zero we find the EPV of the benefits. These quantities, in different markets, will define the costs of changed underwriting classes and of adverse selection (Section 3). 
We used a Runge-Kutta algorithm with step-size 0.0005 years (Conte \& de Boor, 1972).

\subsection{A Remark on the Absence of Onset from the Model}

The model does not represent onset of any disorder, only death. In practice onset might precede death by many years, during which the sufferer would be unable to obtain insurance. In the model, a person can buy insurance right up to the moment of death. This clearly will overstate the cost of adverse selection, so we have dispensed with the extra complexity of modelling onset and survival after onset. Any model of a particular genetic disorder will have to include these, however.

\section{Modelling Severe Late-Onset Disorders}

\subsection{Mutation Frequencies and Population Incidence}

We do not seek to model specific disorders, but late-onset disorders in general in a broad-brush way. In any case, an emerging feature of 'simple' dominantly inherited disorders is that they are not simple; for example several hundred different mutations in at least two genes are involved in familial breast and ovarian cancer, mutations in at least five genes in hereditary non-polyposis colorectal cancer (HNPCC, Pasternak, 1999) and, although Huntington's disease (HD) is caused by a single gene, the defect is a variable number of trinucleotide repeats. Mutation frequencies, in this broad sense, vary from an estimated 1 in 200 for HNPCC to 1 in 1,000 for adult polycystic kidney disease (APKD) to 1 in 10,000 for Huntington's disease (Pasternak, 1999) to 5.3 per 100,000 for autosomal dominant earlyonset Alzheimer's disease (ADEOAD, Campion et al., 1999). Taking $p_{1}=0.96$ and $p_{2}=p_{3}=0.02$ might be very conservative.

\subsection{The Rate of Genetic Testing}

At first sight, the most conservative assumption is that genetic testing should become very common. However, the prevalence of testing is not independent of clinical outcomes. In the absence of effective treatments, rather few people from at-risk families opt to be tested. Tellingly, only $10 \%$ $20 \%$ of people at risk of HD agree to testing (Meiser \& Dunn, 2000). When there are treatments (for example, prophylactic surgery) more people might be tested, and their risk of premature death might drop substantially, but the drastic nature of the intervention may still be a deterrent. Therefore, the most reasonable assumption, reflecting current conditions, is that there is a moderate amount of genetic testing among those at risk. Much higher levels of testing ought to be the result of greatly improved outcomes, and should not make adverse selection any worse. 
Currently reported levels of genetic testing reflect uptake in a clinical setting; possibly some unreported over-the-counter testing could develop, if insurers could access test results. However, since we assume that insurers cannot access test results, we need not account for this explicitly.

We use an annual intensity ${ }^{i} \mu_{x}^{07}=0.02$ to represent a moderate rate of testing, and ${ }^{i} \mu_{x}^{07}=0.10$ to represent a high rate of testing. Even the former is quite high; it implies that within ten years, about $18 \%$ of people at risk have had a test.

\subsection{Elasticity of Demand for Life Insurance}

The numbers of people at risk who buy insurance will presumably be affected by the extra premiums charged. We have no information on the elasticity of demand for insurance, so we consider four possibilities:

(a) in a large market (normal rate of purchase 0.05), people at risk are just as likely to buy insurance despite the extra premium;

(b) in a large market, people at risk are only half as likely to buy insurance (rate of purchase 0.025) because of the extra premium;

(c) in a large market, people at risk buy no insurance; or

(d) in a smaller market (normal rate of purchase 0.01 ), people at risk buy no insurance.

\subsection{Baseline: No Moratorium}

Table 2 shows the EPVs of level and decreasing sums assured per $£ 1$ of loan for ages 20,30 and 40 at entry. The effect of high mutation penetrance is clear.

\subsection{A Moratorium on All Genetic Test Results}

First, suppose that no genetic test result may be used, even if it shows no mutation to be present. We include this for completeness, because it represents a strict interpretation of the ABI's Code of Conduct. All persons at risk will be underwritten on the basis of family history (this is No. 4 in Table 1). The OR class is unchanged, and nobody at risk should be any more likely to buy

Table 2. Expected present values of benefits per $£ 1$ of loan (equivalent to net single premium) for persons taking out term assurance to age 60

\begin{tabular}{|c|c|c|c|c|c|c|}
\hline \multirow{3}{*}{$\begin{array}{l}\text { Mutation } \\
\text { penetrance } \\
\text { by age } 60 \\
\text { (to death) }\end{array}$} & \multicolumn{6}{|c|}{ Expected present value of benefits } \\
\hline & \multicolumn{3}{|c|}{ Level term assurance } & \multicolumn{3}{|c|}{ Decreasing term assurance } \\
\hline & Age 20 & Age 30 & Age 40 & Age 20 & Age 30 & Age 40 \\
\hline$\%$ (not at risk) & 0.02549 & 0.03619 & 0.04620 & 0.01478 & 0.02129 & 0.02856 \\
\hline $25 \%$ & 0.09857 & 0.15789 & 0.15368 & 0.06675 & 0.11923 & 0.11177 \\
\hline $50 \%$ & 0.17242 & 0.27959 & 0.28266 & 0.11873 & 0.21716 & 0.21163 \\
\hline $75 \%$ & 0.24588 & 0.40130 & 0.44030 & 0.17070 & 0.31510 & 0.33369 \\
\hline
\end{tabular}


insurance except, perhaps, after an adverse test result. In terms of the three markets outlined in Section 2.1, the first and second are the same.

Let $B$ and $B^{*}$ be the EPVs of the benefits, in markets with, respectively, no moratorium, or a moratorium with adverse selection (Section 2.1). Let $L$ and $L^{*}$ be the corresponding EPVs of losses. The EPVs of premiums payable are $B-L$ and $B^{*}-L^{*}$ respectively. Therefore $\left(L^{*}-L\right) /\left(B^{*}-L^{*}\right)$ represents the level proportion by which all premiums would have to rise to meet the expected cost of adverse selection. If people buy insurance in the proportions assumed when calculating the premium rate (Section 2.6(a)) $L$ should be zero.

Adverse selection is represented by an annual rate of insurance purchase of 0.25 after receiving a positive test result. This is extremely high; it implies that almost all confirmed mutation carriers buy a house within a few years of being tested, regardless of their economic circumstances, even if they have previously been discouraged by the extra premiums. Non-mutation carriers buy insurance at the same rate before and after a test, since the premium that they are offered is unchanged.

Table 3 shows the resulting increases in the OR premium rate. They are small, even in the smaller market, unless penetrance by age 60 is extremely high. Of course, this is because the additional mortality cost is mostly confined to those with a family history.

Adverse selection increases the premiums of decreasing term assurances by very slightly more than those of level term assurances.

Table 3. Percentage increases in premium rates arising from severe adverse selection; moratoria on the use of genetic test results, family history underwriting still allowed; annual rate of genetic testing 0.02

\begin{tabular}{|c|c|c|c|c|c|}
\hline & & \multicolumn{2}{|c|}{$\begin{array}{l}\text { Level term assurance: } \\
\text { moratorium on using }\end{array}$} & \multicolumn{2}{|c|}{$\begin{array}{l}\text { Decreasing term assurance } \\
\text { moratorium on using }\end{array}$} \\
\hline Description & $\begin{array}{c}\text { penetrance } \\
\text { by age } 60 \\
\text { (to death) } \\
\%\end{array}$ & $\begin{array}{c}\text { All } \\
\text { test } \\
\text { results } \\
\%\end{array}$ & $\begin{array}{l}\text { Adverse } \\
\text { test } \\
\text { results } \\
\%\end{array}$ & $\begin{array}{c}\text { All } \\
\text { test } \\
\text { results } \\
\%\end{array}$ & $\begin{array}{l}\text { Adverse } \\
\text { test } \\
\text { results } \\
\%\end{array}$ \\
\hline Large market: & $\begin{array}{l}25 \\
50 \\
75\end{array}$ & $\begin{array}{l}0.4 \\
0.8 \\
1.2\end{array}$ & $\begin{array}{l}0.4 \\
0.7 \\
1.1\end{array}$ & $\begin{array}{l}0.5 \\
1.0 \\
1.5\end{array}$ & $\begin{array}{l}0.5 \\
0.9 \\
1.3\end{array}$ \\
\hline $\begin{array}{l}\text { Rated-up are } \\
\text { underinsured }\end{array}$ & $\begin{array}{l}25 \\
50 \\
75\end{array}$ & $\begin{array}{l}0.7 \\
1.5 \\
2.4\end{array}$ & $\begin{array}{l}0.6 \\
1.3 \\
2.0\end{array}$ & $\begin{array}{l}0.9 \\
1.9 \\
2.8\end{array}$ & $\begin{array}{l}0.8 \\
1.6 \\
2.4\end{array}$ \\
\hline $\begin{array}{l}\text { Rated-up are } \\
\text { uninsured }\end{array}$ & $\begin{array}{l}25 \\
50 \\
75\end{array}$ & $\begin{array}{l}1.4 \\
3.0 \\
4.8\end{array}$ & $\begin{array}{l}1.1 \\
2.3 \\
3.9\end{array}$ & $\begin{array}{l}1.8 \\
3.7 \\
5.8\end{array}$ & $\begin{array}{l}1.4 \\
2.9 \\
4.7\end{array}$ \\
\hline $\begin{array}{l}\text { Small market: } \\
\text { rated-up are } \\
\text { uninsured }\end{array}$ & $\begin{array}{l}25 \\
50 \\
75\end{array}$ & $\begin{array}{r}4.3 \\
9.0 \\
14.4\end{array}$ & $\begin{array}{r}3.3 \\
7.0 \\
11.4\end{array}$ & $\begin{array}{r}5.4 \\
11.0 \\
17.0\end{array}$ & $\begin{array}{r}4.2 \\
8.7 \\
13.5\end{array}$ \\
\hline
\end{tabular}




\subsection{A Moratorium on Adverse Genetic Test Results Only}

In practice, an applicant who volunteers a negative test result would probably be offered ordinary rates (other underwriting factors permitting). Continuing to treat them as being at risk because of their family history is perhaps strictly logical, but surely untenable. Therefore, suppose such persons are offered ordinary rates after a test (No. 5 in Table 1), and buy insurance normally thereafter. The OR premium will not change, but that based on family history will rise. As well as $B, B^{*}, L$ and $L^{*}$ defined in Section 3.5 , let $B^{\dagger}$ and $L^{\dagger}$ be the EPVs of benefits and losses, respectively, in the market with the moratorium, but without adverse selection. Again, $L^{\dagger}$ should be zero. Then $\left(L^{*}-L^{\dagger}\right) /\left(B^{*}-L^{*}\right)$ represents the proportion by which premiums increase to meet the cost of adverse selection.

Table 3 shows the resulting increases in the OR premium rate. They are slightly smaller than in the case of a moratorium on all genetic test results, because:

(a) the adverse selection is the same, but the cost is spread over an OR class that is slightly larger because it now includes those with a negative test result; and

(b) as those with negative test results join the OR class, the premium rate for those who remain at risk is weighted more towards that of mutation carriers (Section 2.6(a)). It is probably most realistic to assume that this will happen.

Table 3 shows that the financial risks of ignoring some or all genetic test results are small, and probably negligible, provided family history may still be used. It is worth reviewing the extremity of the assumptions that we have made:

(a) $2 \%$ of the population carry dominantly inherited mutations;

(b) mutation penetrance to death by age 60 ranges from $25 \%-75 \%$ in respect of all carriers;

(c) the additional mortality associated with mutations has a linear survival function;

(d) most people who have an adverse test result very soon buy life insurance, despite having previously been discouraged by the extra premium based on family history, which may have been smaller; and

(e) onset is not modelled, so insurance can be bought between onset and death.

The only assumption that might not be adverse in the extreme is the rate of genetic testing, 0.02 per annum. We consider this further in Section 3.8, but, for the reasons given in Section 3.2, this remains our central assumption.

Overall, we conclude that the cost of adverse selection arising from a moratorium that does not extend to family history ought to be negligible. 
3.7 A Moratorium on Family History and Genetic Test Results

Finally, suppose that the moratorium is extended to family history (No. 3 in Table 1). The OR premium rate may increase for two reasons:

(a) People at risk who previously might have been less likely to buy insurance now have equal access to the market, and might be just as likely to buy insurance as anyone else. This is not adverse selection. The market with the moratorium, but without adverse selection, is one in which everyone buys insurance at the 'normal' rate. Let $B^{\dagger}$ and $L^{\dagger}$ be the EPVs of benefits and losses, respectively, in this market. Also, let $B^{\sharp}$ be the EPV of benefits in the market in which nobody at risk buys insurance. If there were only one underwriting class because genetic disorders did not exist, the EPV of the premiums received would be $B ⿱ B^{\sharp} / p_{1}$. Here there is one underwriting class, but it is heterogeneous, so the OR premium rate must rise by a proportion $p_{1} B^{\dagger} / B^{\ddagger}-1$.

(b) An additional increase of $\left(L^{*}-L^{\dagger}\right) /\left(B^{*}-L^{*}\right)$ may be needed if there is adverse selection. We model severe adverse selection by supposing that persons at risk, but untested, or who have an adverse test result, buy insurance at an annual rate of 0.25 . Since the annual rate of testing is only 0.02 , this means that most people at risk buy a house before age 30 . After being tested, non-mutation carriers revert to the 'normal' level of insurance purchase.

Table 4 shows each of these increases separately. Note that the behaviour, before the moratorium, of people at risk is irrelevant, so only the market size matters, but it matters a great deal. The new underwriting classes cost about the same for level and decreasing term assurances, and in large and small markets. Bearing in mind the extremity of our

Table 4. Percentage increases in standard premium rates arising from new underwriting classes and severe adverse selection following a moratorium on the use of adverse genetic test results and family history

\begin{tabular}{|c|c|c|c|c|c|}
\hline & & $\begin{array}{c}\text { Level term } \\
\text { increases }\end{array}$ & $\begin{array}{l}\text { surance: } \\
\text { used by }\end{array}$ & $\begin{array}{c}\text { Decreasing te } \\
\text { increases }\end{array}$ & $\begin{array}{l}\text { assurance } \\
\text { used by }\end{array}$ \\
\hline Description & $\begin{array}{c}\text { Mutation } \\
\text { penetrance } \\
\text { by age } 60 \\
\text { (to death) } \\
\%\end{array}$ & $\begin{array}{c}\text { New } \\
\text { underwriting } \\
\text { classes } \\
\%\end{array}$ & $\begin{array}{c}\text { Severe } \\
\text { adverse } \\
\text { selection } \\
\%\end{array}$ & $\begin{array}{c}\text { New } \\
\text { underwriting } \\
\text { classes } \\
\%\end{array}$ & $\begin{array}{c}\text { Severe } \\
\text { adverse } \\
\text { selection } \\
\%\end{array}$ \\
\hline Large market & 25 & 5.6 & 3.1 & 7.3 & 3.7 \\
\hline & 50 & 11.2 & 5.9 & 14.5 & 6.8 \\
\hline & 75 & 16.8 & 8.5 & 21.8 & 9.7 \\
\hline Small market & 25 & 5.3 & 19.7 & 6.9 & 23.9 \\
\hline & 50 & 10.6 & 37.9 & 13.7 & 45.1 \\
\hline & 75 & 15.9 & 54.7 & 20.6 & 64.2 \\
\hline
\end{tabular}


assumptions, we conclude that the moratorium by itself might increase the OR premium rate by up to $10 \%$, but probably much less. In the larger market, adverse selection costs less than the new underwriting classes; in the smaller market it costs much more. However, again bearing in mind the extreme switch in insurance-buying behaviour, we would give more weight to the lower figures, and suggest that the moratorium and adverse selection together might not increase premiums by more than about $10 \%$ in the larger market, probably by less, though the smaller market might have greater problems. Nevertheless, it is clear that extending a moratorium to family history is potentially much more serious than confining it to genetic tests.

\subsection{Some Sensitivity Tests}

(a) Mutation frequencies. We assumed that $2 \%$ of the population carried mutations of equal severity, not distinguishing between treatable and untreatable disorders. In reality the frequency is much lower, and effective treatments are sometimes available (and may be more effective if genetic tests lead to earlier detection). The costs of adverse selection given a smaller mutation frequency are practically pro rata and we omit examples, but we believe that the costs shown here could be cut by a large factor.

(b) Mutation penetrance as a function of age. For any given penetrance, we expect the same proportion of deaths by age 60 , so the functional form of the additional mortality ${ }^{3} \mu_{x}$ affects the incidence of deaths only. We assumed that, for any given penetrance $P$ by age 60 , the associated survival function is linear. This is severe, and shifts the age at death significantly towards younger ages; it might, therefore, be expected to make adverse selection more expensive. However, there is competition between mortality and insurance purchase; more premature deaths could mean more lives die uninsured. A constant additional force of mortality (equal to $-\log (1-P) / 30$ if deaths take place between ages 30 and 60) might be more realistic, though still quite severe; for most disorders the force of mortality increases with age.

Table 5 shows, for level term assurance only, the effect of this constant force of additional mortality, given a moratorium that includes family history. We omit other moratoria in view of the conclusions already reached. Compared with Table 4, we see that the cost of the new underwriting classes is hardly changed, but the cost of severe adverse selection is somewhat greater, confirming that in this case the removal of lives not yet insured is the stronger influence. Clearly the effect will depend on the circumstances, but it does not seem so great as to alter our conclusions.

(c) Rate of genetic testing. We assumed an annual rate of genetic testing of 0.02 , that we believe is more realistic than a higher rate in the absence of 
Table 5. Percentage increases in standard premium rates arising from new underwriting classes and severe adverse selection following a moratorium on the use of adverse genetic test results and family history; level term assurance, and constant force of additional mortality

\begin{tabular}{|c|c|c|c|}
\hline & & \multicolumn{2}{|c|}{ Increases caused by } \\
\hline Description & $\begin{array}{c}\text { Mutation } \\
\text { penetrance } \\
\text { by age } 60 \\
\text { (to death) } \\
\%\end{array}$ & $\begin{array}{c}\text { New } \\
\text { underwriting } \\
\text { classes } \\
\%\end{array}$ & $\begin{array}{c}\text { Severe } \\
\text { adverse } \\
\text { selection } \\
\%\end{array}$ \\
\hline Large market & 25 & 5.6 & 3.2 \\
\hline & 50 & 11.7 & 6.7 \\
\hline & 75 & 18.4 & 10.8 \\
\hline Small market & 25 & 5.4 & 20.5 \\
\hline & 50 & 10.9 & 41.5 \\
\hline & 75 & 16.7 & 64.9 \\
\hline
\end{tabular}

effective treatments. We suggested that higher rates will follow medical advances, so that adverse selection will not be an issue. Nevertheless, we have repeated the calculations with an annual rate of genetic testing of 0.10 . Table 6 shows the costs of adverse selection with moratoria on genetic tests alone, for level term assurances (for brevity, we omit decreasing term assurances in this section).

Table 6. Percentage increases in premium rates arising from severe adverse selection; moratoria on the use of genetic test results, family history underwriting still allowed; level term assurance, and annual rate of genetic testing 0.10

\begin{tabular}{|c|c|c|c|}
\hline & & Morat & n using \\
\hline Description & $\begin{array}{c}\text { Mutation } \\
\text { penetrance } \\
\text { by age } 60 \\
\text { (to death) } \\
\%\end{array}$ & $\begin{array}{c}\text { All } \\
\text { test } \\
\text { results } \\
\%\end{array}$ & $\begin{array}{c}\text { Adverse } \\
\text { test } \\
\text { results } \\
\%\end{array}$ \\
\hline arge market: & 25 & 1.2 & 0.3 \\
\hline & 50 & 2.3 & 0.7 \\
\hline & 75 & 3.5 & 1.0 \\
\hline ated-up are & 25 & 2.0 & 0.6 \\
\hline hderinsured & 50 & 4.1 & 1.1 \\
\hline & 75 & 6.3 & 1.7 \\
\hline ated-up are & 25 & 4.0 & 0.8 \\
\hline hinsured & 50 & 7.7 & 1.7 \\
\hline & 75 & 12.1 & 2.7 \\
\hline mall market: & 25 & 10.7 & 2.3 \\
\hline d-up are & 50 & 21.2 & 4.2 \\
\hline hinsured & 75 & 32.5 & 6.3 \\
\hline
\end{tabular}


We do not consider the moratorium on family history and genetic tests; once everyone has access to the same rate of premium there is no reason to suppose that a test result will make such a difference, unless the decision whether or not to buy insurance were to become a primary reason for having a test. In that case, Table 4 still gives some idea of the outcomes.

Compared with Table 3, we see that the higher rate of testing could increase or decrease the cost of adverse selection. If negative test results may not be used, the numbers buying insurance after a positive test increase, as does the cost. If they may be used, the at-risk underwriting class becomes more heavily weighted by mutation carriers, the premium that they are charged increases and the cost falls. Therefore, the rate of genetic testing has an effect that depends on the details of the moratorium. In either case, however, the difference is not large enough to alter our conclusions.

(d) Rate of insurance purchase with adverse information. We assumed that insurance purchase, whenever it is influenced by undisclosed adverse genetic information, took place at an annual rate of 0.25 , regardless of the market size. This is extremely high: five times the 'normal' rate in the large market and 25 times the 'normal' rate in the smaller market. It ignores the actual financial circumstances of the people concerned. Table 7 shows, for level term assurances, the effect of reducing this rate to a more moderate 0.10 (still ten times the 'normal' rate in the smaller market). Again, we omit moratoria on test results alone. The cost of redefining the underwriting classes is unchanged, while the cost of

Table 7. Percentage increases in standard premium rates arising from new underwriting classes and severe adverse selection following a moratorium on the use of adverse genetic test results and family history; level term assurance, and rate of insurance purchase given adverse information 0.10 instead of 0.25

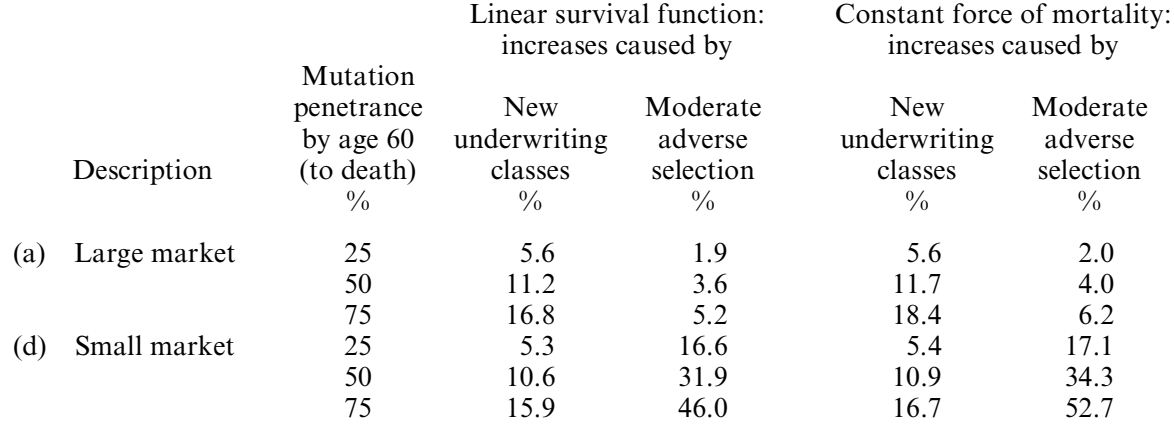


adverse selection is reduced, but not by so much as to change any conclusions. In particular, adverse selection might still be expensive in the smaller market.

\subsection{A Comment on Market Size}

Our illustration of the smaller market should not be interpreted as the worst that could happen. In a market smaller still, for example one in which only a small proportion of the whole population had any interest, these could more realistically represent the impact of a very small number of adverse selectors. Our conclusions are only in respect of mortgage-related life insurance and must not be extrapolated to, for example, critical illness insurance (a smaller market in which the higher penetrances, to onset rather than to death, might be more realistic) or long-term care insurance (for which the market is very small). In view of the HGC's ongoing interest, further research is needed urgently into specific genetic disorders and other forms of insurance.

\section{Conclusions}

\subsection{Different Types of Moratoria}

While many of our assumptions have been hypothetical, or deliberately extreme, we have modelled underwriting classes (in respect of Mendelian disorders) more realistically than before. In particular, we have allowed explicitly for family history as well as for genetic testing. We have illustrated the effects of three kinds of moratoria on the use of genetic information in underwriting mortgage-related life insurance. This is a simple class to choose, because the market in the U.K. is large, and the link to house purchase, we assume, reduces the problem of adverse selection to rates of insurance purchase. We measured the cost of adverse selection by the percentage increase in the OR premium rate:

(a) A moratorium on all genetic test results allows adverse selection, but its cost should be negligible unless our most extreme model of genetic epidemiology is realistic, and only in a smaller market.

(b) More realistically, people with negative test results might be allowed OR premium rates. The costs of adverse selection then decrease, because we suppose that the premium rate for those remaining at risk will be adjusted to reflect the loss of these people to the OR class. As this is perhaps closest to the current position, it remains unclear why the ABI advised its members that they might continue to use genetic test results prior to approval by GAIC (Section 1.3).

(c) A moratorium extended to family history may be expected to increase premium rates even with no adverse selection. This increase should not depend much on market size, and, unless our more extreme 
epidemiological model is realistic, we suggest that it should be well under $10 \%$. Adverse selection might cause further increases, which in a smaller market could be significant, but in the larger market we suggest that the combined increase should be under $10 \%$. This should be compared with the very large falls in premium rates over the last few decades, reflecting general improvements in mortality.

Previous studies found above-average sums assured to be a significant part of adverse selection. We have ignored that here because of the link to house purchase. Were it included, the premium increases would be greater, roughly in proportion to the excess above the average amount insured (see Macdonald, 1997, 1999). The costs of adverse selection in this model then might be high enough that a more detailed, and less extreme, epidemiological model would be needed to draw reasonable conclusions. In this context, we note the 'ceilings' on the moratorium in use in the U.K. (Section 1.3).

\subsection{Level or Decreasing Term Assurance}

We found that adverse selection presents a slightly greater problem for decreasing term assurance than for level term assurances, but the differences were not large.

\subsection{The Prevalence of Genetic Testing}

The prevalence of genetic testing is not a significant factor if family history may be used in underwriting. This is because its only effect is to modify the composition of the rated-up underwriting class, not necessarily to the disadvantage of the insurer. If a moratorium were extended to family history, it could conceivably become important, if tests were taken specifically in order to decide whether or not to buy insurance. Given the carefully controlled clinical setting in which genetic testing currently takes place in the U.K. and the link to house purchase, this might be thought unlikely, but that background could change.

\subsection{Family Histories of Complex Disorders}

We have only considered family histories of Mendelian disorders, not of complex disorders such as heart disease. The latter may indicate a mixture of genetic and environmental influences, including shared circumstances like wealth. Family histories of complex and of Mendelian disorders are different in kind, and our conclusions have no relevance in respect of the former.

\subsection{Critical Illness Insurance}

Although we have modelled mortality, some rough idea of the effect of moratoria on critical illness (CI) insurance may be obtained also. The higher penetrances are then more relevant, since onset and not death is the event 
insured against; the market is smaller than that for life insurance; and the link with house purchase is much weaker. Clearly, further work is needed on CI insurance.

\section{REFERENCES}

Association of British Insurers (1999). Genetic testing: ABI code of practice (revised August 1999). Association of British Insurers, London.

Campion, D., Dumanchin, C., Hannequin, D., Dubois, B., Belliard, S., Puel, M., ThomasAnterion, C., Michon, A., Martin, C., Charbonnier, F., Raux, G., Camuzat, A., Penet, C., Mesnage, V., Martinez, M., Clerget-Darpoux, F., Brice, A. \& Frebourg, T. (1999). Early-onset autosomal dominant Alzheimer disease: prevalence, genetic heterogeneity, and mutation spectrum. American Journal of Human Genetics, 65, 664-670.

Conte, S.D. \& De Boor, C. (1972). Elementary numerical analysis. McGraw-Hill, New York.

House of Commons Science And Technology Committee (2001). Fifth report: Genetics and insurance. http://www.publications.parliament.uk/pa/cm200001/cmselect/ cmsctech/174/17402.htm

Human Genetics Advisory Commission (1997). The implications of genetic testing for insurance. Human Genetics Advisory Commission, London.

Human Genetics Commission (2001). The use of genetic information in insurance: Interim recommendations of the Human Genetics Commission. http://www.hgc.gov.uk/ business $\backslash$ ppublications $\backslash \_$statement $\backslash$-01may.htm

Macdonald, A.S. (1997). How will improved forecasts of individual lifetimes affect underwriting?. Philosophical Transactions of the Royal Society B, 352, 1067-1075, and (with discussion) British Actuarial Journal, 3, 1009-1025 and 1044-1058.

Macdonald, A.S. (1999). Modeling the impact of genetics on insurance. North American Actuarial Journal, 3:1, 83-101.

Macdonald, A.S. \& Pritchard, D.J. (2000). A mathematical model of Alzheimer's disease and the ApoE gene. ASTIN Bulletin, 30, 69-110.

Macdonald, A.S., Waters, H.R. \& Wekwete, C.T. (2003). The genetics of breast and ovarian cancer I: a model of family history. Scandinavian Actuarial Journal, 2003, 1-27.

Meiser, B. \& Dunn, S. (2000). Psychological impact of genetic testing for Huntington's disease: an update of the literature. J. Neurol. Neurosurg. Psychiatry, 69, 574-578.

Pasternak, J.J. (1999). An introduction to human molecular genetics. Fitzgerald Science Press, Bethesda, Maryland.

Pritchard, D.J. (1997). Life assurance: financial implications of a change in insuring behaviour resulting from individuals' increased knowledge of their genetic predispositions. MSc dissertation, Heriot-Watt University, Edinburgh.

Subramanian, K., Lemaire, J., Hershey, J.C., Pauly, M.V., Armstrong, K. \& Asch, D.A. (2000). Estimating adverse selection costs from genetic testing for breast and ovarian cancer: the case of life insurance. Journal of Risk and Insurance, 66, 531-550.

YANG, S. (2000). Some investigations into the rate at which life insurance is purchased in the U.K. MSc dissertation, Heriot-Watt University, Edinburgh.

Zimmern, R. (2001). What is genetic information? Genetics Law Monitor, 1:5, 9-13. 